\title{
Din Sosyolojisinde Dindarlı̆̆ın Ölçülmesi Problemi Üzerine Bir Araştırma
}

\author{
HAKKI KARAŞAHIN \\ DR., INÖNÜ Ü. İLAHIYAT FAKÜLTESI \\ e-posta: hakkikarasahin@hotmail.com
}

\begin{abstract}
A Study on the Problem of Religiosity Measurement in the Sociology of Religion. In this study, the basic theme of interest comprised the factors such as the religiosity and dimension of religiosity in the sociology of religion and also the problem how to measure the religiosity from the sociological perspective. Those criticisms which are directed on the issues such as the definitions of religiosity, measurement of religiosity and dimensions of religiosity expressed by the sociology of religion, were reviewed. Briefly, main purpose of the study is to examine what sort of change has been experienced. Also, in the study, it is studied empirical research tendency that has turned the religiosity into a subject of research for the sociology of religion.
\end{abstract}

key words

Sociology of Religion, Religiosity, Dimensions of Religiosity, Measurement of Religiosity.

\section{Problem}

Din sosyolojisi çalışmalarında din fenomenini hem teorik hem de empirik bir temele dayalı olarak inceleme eğilimi artmıştır. Geleneksel teorilerle olgu arasındaki uyumsuzluğa cevap olarak gelişmiş bu eğilim, empirik araştırma bulgularının yorumuna yönelik olarak yapılanmıştır ${ }^{1}$. Dini, empirik ve gözlemlenebilir sosyal bir olgu olarak ele alan din sosyolojisi eğilimi, bir toplumda dinin rolü ve önemini anlamak ve açıklamak için sosyolojik

1 Rodney Stark- Roger Finke, Acts of Faith, Berkeley, Los Angeles, London, 2000, s. 27-28. 
bir perspektif uygulamıştır². Dinin topluma veya toplumun da din üzerine etkilerinin sosyolojik olarak nasıl incelenmesi gerektiği problemi, bu eğilimi benimseyen bir çok sosyologun ilgisini çekmiştir. Bunun için dinî hayatın tek boyutlu veya çok boyutlu olarak incelenmesi gerektiği tartışmaları sürüp gitmiştir. Din sosyolojisindeki bu yönelime bağlı olarak dindarlık ve dindarlığın boyutları gibi kavramlar temel ilgi konusu olmaya başlamıştır.

Din sosyolojisinde dindarlık olgusunu empirik araştırma konusu olarak inceleyen bu yönelim, nasıl bir değişim süreci geçirmiştir? Empirik çalışmaların veri toplama araçları olan dindarlık ölçeklerine ve bu ölçeklerin ayırt ettiği dindarlık boyutlarına ne tür eleştiriler yapılmaktadır? İşte bu araştırma, bu problemlerin çözümüne eğilmektedir.

\section{Dindarlık}

Din sosyolojisi araştırmalarında "dindar olma" kavramının bir çok tanımı yapılmıştır ${ }^{3}$. Johnstone'a göre dindarlık tanımı, dinin tanımı esas alınarak yapılabilir. Buna göre din, dinî grup üyeleri tarafından paylaşılan kutsal ve aşkın güçlere inanmaya odaklanmış inançlar ve pratikler bütünüdür. Dindar ise belirli aşkın ve kutsal şeylere inanan, bu inançlar doğrultusunda belirli aktiviteler yapan ve dinî bir grup üyesi olan herkes dindardır ${ }^{4}$. Günay ise dindarlığı, "kutsal olanın yahut özel bir formu olmak itibariyle belli bir dinin muayyen bir zaman ve şartlarda belli bir kişi veya grup ya da toplum tarafından yaşanmasıdır", kısaca "yaşanan din" şeklinde tanımlamaktadir 5 .

Sosyologlar, dindarlığın tanımındaki zorluğu aşabilmek için iki yaklaşım geliştirmişlerdir. Nitekim, Batı'da yapılan bazı empirik din sosyolojisi çalışmalarında dindarlık, dinî gurup üyeliği ve bireysel tutumlardaki dinî farklılaşma esasına bağlı olarak tanımlanmaya çalışılmıştır. Birinci yaklaşımin merkezinde, insanların dinî organizasyonlar veya guruplarla bağlantıları yer alır. Bu yaklaşımdan hareket eden bazı sosyologlar, insanların tutum ve davranışlarındaki farklılıkları, dinî grupla ilişkilerine göre gözleme-

2 Michele Dillon, "The Sociology of Religion in Late Modernity", Handbook of the Sciology of Religion, (ed. Michele Dillon), Cambridge, 2003, s. 7.

3 M.Emin Köktaş, Türkiye'de Dinî Hayat, İstanbul, 1993, s.62-67; Ali Ulvi Mehmedoğlu, Kişilik ve Din, İstanbul, 2004, s.30-31; Kemaleddin Taş, "Dindarlığın Kriterleri Üzerine Tipolojik Bir Araştırma”, Dindarlığın Sosyo-Psikolojisi, (eds. Ünver Günay-Celaleddin Çelik), Adana, 2006, s. $176-178$.

4 Ronald L. Johnstone, Religion in Society, New Jersey, 1992, s.58-60.

5 Ünver Günay, "Dindarlığın Sosyolojisi", Dindarlığın Sosyo-Psikolojisi, (eds. Ünver Günay-Celaleddin Çelik), Adana, 2006, s. 22. 
ye ve ölçmeye teşebbüs etmişlerdir. Teknik olarak bu yaklaşım, dindarlıktan daha çok organizasyonun ve dinî grupların kendisine odaklanır. İkinci yaklaşımda ise bireysel özellikler, eğilimler ve bazı değişkenler vasıtasıyla dindarlık tanımlanır ${ }^{6}$.

1930'ların başlarından itibaren dindarlık ve dinî çevre çeşitliliği, empirik olarak incelenmeye başlanmıştır ${ }^{7}$. Dinî grup üyeliği merkezli dindarlık tanımından hareket eden bu tür çalışmalarda bireysel ve toplumsal dindarlık farklılaşması tek boyutlu olarak tanımlanmaya ve ölçülmeye çalışılmıştır. Öncelikle dinî gurup üyeliği yaklaşımında büyük dinî aileler, Katolik, Protestan, Yahudi veya Hindu, Müslüman, Budist ve Hıristiyan gibi kategorilere ayrılmıştır. Daha sonra araştırmada bu tür büyük dinî grupların frekans dağılımları betimlenmiştir. Survey tekniği ile yapılan bu tip çalışmalar dışında daha küçük örneklem üzerine yoğunlaşan bazı empirik din sosyolojisi araştırmalarında büyük dinî guruplara göre örneklemin dağılımı ile birlikte farklı kanaat, tutum ve davranışlar gösterilmeye çalışılmıştır ${ }^{8}$. Örneğin, Robert ve Helen Lynd, dindarlık farklılaşması ile sınıf arasındaki ilişkileri betimlemişlerdir. Alt sınıfın kilise üyeleri arsındaki dağılımı orta sınıftan daha düşük olmasına rağmen her iki sınıftakilerin kilise üyelerinin oranı üst sınıfa göre daha yüksek olduğu görülmüştür ${ }^{9}$. Ancak, bu tip araştırmalarda büyük dinî gruplar arasındaki kanaat, tutum ve davranış farkl1laşmasına yönelik ulaşılan bulgulardan sadece bir kaçı rapor edilebilmiştir. Sonuç olarak dinî guruplar arasındaki formel dinî farklılık ölçekleri, inanç ve doktrin farklılıklarını ölçmeye odaklanmıştır. Bu tip dindarlık ölçekleri, dinî ilginin derecesi ve inanç yoğunluğu, dinî cevap ve çözümleri ve dinî katılım gibi bireysel dindarlığı göz ardı etmişlerdir ${ }^{10}$.

Diğer taraftan surveylerde örneklem ne kadar büyük olursa olsun büyük dinî grupların alt kategorileri ile ilgili yeterli büyüklükte örnekleme ulaşılamamıştır. Protestanlık, Katoliklik gibi büyük dinî gruplarla ilgili yeterli örnekleme ulaşılsa bile bunların alt kategorileri arasındaki dinî farklılaşmaları temsil edecek ayrıntıda ve yapıda örneklem de seçilememiştir. Örneğin, Uniteryanlar ve Mennonitler gibi alt kategoriler, Protestan olarak isimlendirilmesine rağmen neredeyse birbirine zıt iki gruptur. Bu yüzden Glock ve Stark, başka bir araştırma stratejisi geliştirmiştir. Onlar, Protes-

6 R.L. Johnstone, a.g.e., s.59-60; M.E. Köktaş, a.g.e., s. 62-66.

7 N.J. Demerath, "Religion and Social Class in America", Sociology of Religion, (edit, Roland Robertson), New York, 1976, s. 336.

8 R.L. Johnstone, a.g.e., s. 60-61.

9 N.J.Demerath III, a.g.m, s. 337

10 R.L. Johnstone, a.g.e., s. 63. 
tanlığın alt mezheplerini çalışmaya başladıklarında dinî grup üyeliğini bağımsız değişken olarak kullanarak, Metodistler, Lutheryanlar, Baptistler ve Episkopalyanlar gibi Protestan mezheplerini temsilen seçtikleri daha küçük örneklemden bunlar arasındaki dindarlık farklılaşmaları hakkında etkileyici bulgular elde etmişlerdir ${ }^{11}$.

\section{Dindarlık Ölçekleri}

1940'ların başından itibaren empirik çalışmalarda bireyin kiliseye katılım sıklığı ve inancı uygulama yoğunluğu dindarlık ölçütü olarak kullanılmış$\operatorname{tır}^{12}$. Dindarlık, bireyin dinî pratiklere bağlılığı ile tasvir edilmiştir. Belirli bir dini sisteme inanan bireylerin, inançlara ve ibadetlere bağlılık sıklığına göre dindarlık tanımına gidilmiştir. Her hafta veya neredeyse her hafta ayine katılanlar, yüksek düzeyde dindar, ayda bir veya iki ayda bir katılanlar, orta düzeyde dindar, bu katılım düzeylerinden daha az katılanlar ise düşük düzeyde dindar olarak sınıflandırılarak rapor edilmişlerdir. Bu ölçeklerde orta derecede yüksek ve orta derecede düşük dindar gibi tipler de ilave edilerek beş veya yedi tip kullanılmıştır ${ }^{13}$.

Bununla birlikte bazı sosyologlar, bireyin ritüellere katılım sıklığı göstergesine bağlı istatistiklerin gerçek dindarlığı ölçmede yetersiz kaldığını ileri sürmüşlerdir. Onlara göre bu tür istatistikler, ritüellere katılımla ilgili olarak bireyin ne hissettiği hakkında hiçbir şey söyleyemezler. Nitekim bireyler, alışkanlık sonucu, aile veya başka sosyal gurupların etkisiyle ritüellere düzenli olarak katılabilirler. Bu nedenle kilise ayinlerine katılım sıklığı yanında "hayatınızda din ne kadar önemli" veya "sizin için kilise üyeliği ne kadar önemli" gibi maddeler ile "çok önemli", "biraz önemli", "önemli değil", "hiç önemli değil" gibi seçeneklere verilen cevaplara bağlı olarak, bireyin hayatında dinin anlam ve önemi ölçülmüşsür ${ }^{14}$. Bir araştırmada dindarlığın göstergesi olarak ibadet alınırsa ve bu göstergeye göre toplumun dindarlığı değerlendirilirse elde edilen bulgular hiç de güvenilir değildir ${ }^{15}$. Nitekim Berger, kiliseye devam, kilisede evlenme gibi göstergelerden hareketle dindarlığı inceleyen bu tip araştırmaları "piyasa araştırması" olarak nitelemiş ${ }^{16}$, Luckmann da bunların çoğunun kilise yönelimli dindarlığın

11 R.L. Johnstone, a.g.e.,s. 61-62.

12 N.J.Demerath III, a.g.m, s. 341

13 R.L. Johnstone, a.g.e., s. 58-60.

14 R. L. Johnstone, a.g.e., s. 64-65

15 Ian Thompson, Odaktaki Sosyoloji Din Sosyolojisine Giriş, (çev. Bekir Zakir Çoban), İstanbul, 2004, s. 23

16 Peter L. Berger, Dinin Sosyal Gerçekliği, (çev. Ali Çoşkun), İstanbul, 1993, s. 228. 
ölçülebilir öteki unsurlarını göz ardı ettiklerini ve "kilise ile dinin özdeşleştirildiğini" ileri sürmüştür ${ }^{17}$.

Din sosyolojisinde 1960'ların başlarına kadar, dindarlık problemi üzerine bazı tartışmalar yapıla gelmiştir. Bu yıllarda sosyologlar, Katoliklik, Protestanlık ve Yahudilik gibi büyük dinî guruplar arasındaki tutum, davranış ve kanaat farklılaşmalarını göstermeye çalışırken, bu kadar büyük ve kendi içerisinde bile oldukça karmaşık önemli farklılaşmaları barındıran bu kategorileri, bütünüyle açıklamanın güç olduğunu fark etmişlerdir ${ }^{18}$. Bu yüzden Glock ve Stark'ı takip eden bir çok sosyolog dindarlığın, eğitim, ekonomi, siyaset, etnisite gibi değişik değişkenlerle ilişkileri üzerine yoğunlaşarak, araştırma stratejilerini geliştirmeye başlamışlardır. Bu yaklaşımı, ilk kez Protestan mezhepleri üzerine uygulayan Glock ve Stark, bu mezhepler arasında köklü inanç farklılaşmasının olduğunu keşfetmiştir ${ }^{19}$.

1960'lardan itibaren dindarlığın çok boyutlu olarak incelenmesi gerektiği ileri sürülmüştür. Nitekim, ilk defa Fichter, Paris'te Katoliklik üzerine yaptığ bir araştırmada, "nükleer Katolik", "şekilci Katolik", "marjinal Katolik" ve "cansız (dormant) Katolik" şeklinde dört dindarlık boyutu kullanmıştır ${ }^{20}$. Lenski ise dindarlığı, "sosyo-dinî gurup" ve "dinî yönelim" şeklinde iki boyuta ayırmıştır. Sosyo-dinî gurup boyutunu ise birlikte toplu olarak yapılan ibadetlere katılımı işaret eden "cemaate (associational) bağl1lık" ve aile, arkadaşlık gibi bireyin ait olduğu sosyal guruplar ve sosyal çevre ile sınırlandırılan, birincil sosyal ilişkilerin dinî hayata etkilerini açıklayan "topluluğa (communal) bağlılık" olarak iki alt boyutta ele almıştır. Aynı şekilde dinî yönelim boyutunu da, ortodoks doktrin, (kiliselerin emrettiği doktrinleri kabul edenler), "zühd (devotionalism)" (Tanrı ile özel ve kişisel iletişim), olmak üzere iki boyutta incelemiştir ${ }^{21}$. Luckmann, "ayinlere katılım", "kiliseyle subjektif özdeşleşme", "ortodox", "kilise hizmetlerine katılım" şeklinde dindarlığın dört boyutunu belirlemiştir. Luckmann, ortodoks boyutun, "objektif" (doktirin veya normlarla ilgili tutumları niteler), "subjektif" (doktrinin özel yorumunu karakterize eder) şeklinde iki alt boyutunu ayırt etmiştir.

Allport'un, 1954 yılında geliştirdiği "dinî yönelim ölçeği”, empirik araştırmalar için öncü bir dindarlık ölçek modeli olarak kabul edilmiştir. Onun

17 Thomas Luckmann, Görünmeyen Din, (çev. Ali Çoşkun-Fuat Aydın), İstanbul, 2003, s. 20-21.

18 R.L. Johnstone, a.g.e., s. 61.

19 Charles Y. Glock-Rodney Stark, Anti-Semitism in America, New York, London, 1979.

20 R.L. Jhonstone, a.g.e., s. 66-67.

21 Gerhard Lenski, The Religious Factor, Garden City, New York, 1963, s. 18-25. 
teorisine göre dindarlık, "içe dönük" ve "dışa dönük" olmak üzere iki boyuta ayrılmıştır. Allport'un bu yaklaşımı, daha sonra Feagin ${ }^{22}$, Allport-Ross ve birçok araştırmacı tarafından cinsiyet farkı, dogmatizm, feminizm, ölüm korkusu ve dindarlık gibi değişik değişkenlerle ilişkileri incelenmiştir. Allport ve Ross, dinî yönelim ölçeğinden alınan puana göre "içe dönük dindar", "dışa dönük dindar", "ayrımsız dindar" ve "ayrımsız bir şekilde dine karş1 ya da dindar olmayan" şeklinde dört boyut belirlemiştir ${ }^{23}$.

Thouless, 40 maddeden oluşan "dinî inançlarda kesinlik ölçeğini", çeşitli dinî inançlardaki kesinliği saptamak amacıyla dizayn etmiştir. Sıkala'yı geçerlilik ve güvenirlilik çalışması yapmadan Glasgow üniversitesinde seçtiği örneklem üzerinde 95 erkek, 45 kadın öğrenciye uygulayan Thouless, her maddeye likert tipi altılı bir cevap seçeneği sunmuştur. Verilen cevaplar +3 ve- 3 arasında değişen şekilde puanlanmıştır. Buna göre tamamen kesin inançlı veya tamamen inancı karasız şeklinde iki tip ayırt etmiştir. Ancak, Thouless sıkalasının geçerlilikten ve güvenirlilikten yoksunluğu, başka çalışmalarda daha fazla kullanılmasını engellemiştir ${ }^{24}$. Brown ve Lowe, Hıristiyan inançlarını kabul veya red derecelerini ölçe bilmek için "dinî inançlar envanteri” ölçeğini geliştirmiştir. Ölçekte 15 madde yer almış ve 5'li likert tipi cevap seçenekleri sunulmuştur. Geçerlilik ve güvenirlilik çalışmaS1 yapılan ölçek Denver üniversitesinde 887 öğrenci üzerinde uygulanmıştır. Bütün bunlara rağmen Brown ve Lowe'nin ölçeği, dindarlı̆̆ın diğer boyutlarına karşı tutumları kapsamadığı için oldukça sınırlıdır ${ }^{25}$. İngiltere kolej öğrencilerinin dinî tutumlarını ölçmeyi amaçlayan Poppleton ve Pilkington, "Thurstone ölçeğinden" yararlanarak, "dinî tutumlar ölçeği" geliştirmişlerdir ${ }^{26}$. Boren, dindarlık kavramı içinde önemli faktörlerin olup olmadığını keşfetme ile ilgilenmiştir. O, "Tanrı'ya yakınlık" ve "fundemantalizm" olmak üzere iki faktör bulmuştur. Bu faktörleri ise "genel dindarlık" ve "şiddetli dinî farklılaşma" şeklindeki iki boyutlu ölçekle tasvir etmiştir ${ }^{27}$.

Putney ve Middleton, 1200 üniversite ve kolej öğrencisi üzerine yaptı̆̆ 1 araştırmada dindarlığın ideoloji boyutunu, "ortodoks", "fanatizim”, "önem” ve "kararsız" olmak üzere dört tipte ele almışlardır. Her bir ideolojik boyut alt skalalarla ölçülmüştür. Ölçekte, Ortodoks, fanatizim ve önemlilik bo-

22 ROBINSON, Jhon P.-SHAVER, Phillip R., Measures of Social Psychological Attitudes, Michigan, 1972, s.616.

23 Ahmet, Onay, Dindarlık Etkileşim ve Değişim, İstanbul, 2004, s. 47-49.

24 J. P. Robinson-P. R. Shaver, a.g.e., s. 596.

25 J.P. Robinson-P.R. Shaver, a.g.e., s. 603-604.

26 J.P. Robinson-P.R. Shaver, a.g.e., s. 607.

27 J.P. Robinson-P.R. Shaver, a.g.e., s. 585. 
yutlarının her biri için 6'şar madde, kararsız boyutunda ise bir madde olmak üzere toplam 19 madde yer almıştır. Maddeler için yedili likert tipi cevap seçenekleri verilmiştir. Putney-Middleton'un, ideolojik alt faktörlerinden yararlanmak mümkün olmasına rağmen kararsızlık sıklasının geçerlilik ve güvenirliliğinin artırılması gereklidir. Aynı şekilde dinî davranışın diğer boyutlarını göz ardı etmektedir. Yine de bu ölçek dindarlı̆̆ın ideoloji, ritüel veya inanç gibi tek bir boyutunun en iyi şekilde nasıl ölçülmesi gerektiğini göstermesi bakımından önemlidir ${ }^{28}$.

King, 1967 yılında yaptı̆̆ 1 araştırmada dokuz boyutlu dindarlık ölçeği geliştirmiştir ${ }^{29}$. King Dallas'da methodistlerden seçtiği 575 kişilik örneklem üzerinden elde ettiği dataya uyguladığı bir dizi analiz neticesinde dindarlığın tek boyutlu olduğu hipotezini redderek, dokuz boyut önermiştir. Ancak, King, 1969 yllında Hunt'la birlikte aynı data üzerinde bilgisayar teknikleri uygulayarak gerçekleştirdikleri faktor analizi sonucu dindarlığın 11 boyutunu belirlemiş̧lerdir. Bunlar: 1. İnançları onama, 2. Kişisel dinî tecrübe, 3. Kiliseye katılma, 4. Dinî gurup organizasyonlarına katılma, 5. Kilise işlerinde çalışma, 6. Din hakkında okuma ve konuşma 7. Finansal destek, 8. Dinî bilgi, 9. Dinî gelişmeye yönelim, 10. Dinî güvenlik ve dogmatizme yönelim, 11. Dışa yönelim ${ }^{30}$. King ve Hunt'nn sıkalası daha sonraki araştırmalar için iyi bir temel sağlamaktadır. Zaten onların tespit ettikleri bir çok boyut, daha önce Glock, Lenski ve Fukuyama gibi sosyologlar tarafından önerilen boyutlara benzerdir. Bununla birlikte King'in tamamıyla Metodistlerden oluşan örneklemi oldukça sınırlı ve dindarlığın boyutlarını keşfedebilmek için yeterli bir gurup değildir. Maddeler, seçilmiş örneklemden daha çok yaygın nüfusa uygulanmak amacıyla kasten seçilmiştir. Nitekim King, aynı dindarlık boyutlarının diğer dinî mezheplerin üyeleri için de türetilebileceğini göstermektedir. Öncelikle maddeler, kilise inançları ve aktiviteleriyle ilişkilendirilmiştir. Yani dindarlığın kişisel görünümlerinden daha çok sosyal yönüne vurgu yapılmıştır ${ }^{31}$. Faulkner ve DeJong ise Glock ve Stark'ın önerdiği dindarlığın beş boyutunu ölçmeye çalışmıştır. Onlar, öncelikle davranış ölçen maddeler kullanmışlardır. Pensilvanya üniversitesi öğrencilerinden tesadüfï örneklem tekniği ile seçtikleri 89 öğrenci üzerinde ön araştırmadan elde ettikleri datadan hareketle anlaşılma-

28 J.P. Robinson-P.R. Shaver, a.g.e., s. 577-578.

29 M.B. King, "Measuring the Religious Variable: Nine Proposed Dimensions", Journal for the Scientific Study of Religion, Say1,6, 1967, s. 173-190.

30 M.B. King-R.A.Hunt, "Measuring the Religious Variable: Amended Findings", Journal for the Scientific Study of Religion, Say1,8, 1969, s. 321-323.

31 J.P. Robinson-P.R. Shaver, a.g.e., s. 570-572. 
yan maddeleri yeniden düzenlemişler ve ölçekteki eksikleri gidermişlerdir. Ölçeğin güvenirlilik analizi sonucu "inanç", "ritüel", "bilgi", "tecrübe" ve "etki" şeklinde beş tane dindarlık boyutuna ulaşmışlardır ${ }^{32}$.

Dindarlığın çok boyutlu bir fenomen olduğunu ilk keşfeden Glock olmuştur $^{33}$. Glock'a göre din, ister ilkel isterse modern toplumlarda olsun değişik anlamlar kazanır. Nitekim, din, bir dinî geleneğe bağlı insanlar için bile çok farklı anlamlara gelir. Halbu ki, bugüne kadar yapılan araştırmalarda dindarlığın inanç problemi, inançların anlamı veya çeşitli dinî pratikler gibi boyutlarından birisi üzerinde yoğunlaşılmış ve dindarlığın bütün tezahürleri kavranamamıştır. Bu nedenle dinî zihniyet ve bağlılıkları kapsamlı bir şekilde açıklaya bilmek için dindarlığın farklı ifade şekilleri ve tezahürleri dikkate alınmalıdır. Glock'a göre her ne kadar çeşitli dünya dinlerinin oldukça farklı tezahürleri olsa da bu dinlerde dindarlığın ifade edildiği genel boyutlarda bir uzlaşma mümkündür. Önce, dünya dinlerinde ortak olan dindarlığın dört boyutunu belirleyen Glock, daha sonra Stark'la birlikte yaptıkları araştırmada dindarlığı beş boyutta açıklamıştır. Glock ve Stark, çeşitli dünya dinlerinde ortak olarak gördükleri, "inanç, ibadet, tecrübe, bilgi ve etki" şeklindeki dindarlığın beş boyutunu birbirinden ayırt etmişler ve bunları temel alarak yapılan dindarlık ölçümlerinin dinî hayatı daha şumullü bir şekilde açıklayacağını ileri sürmüşlerdir ${ }^{34}$. Bu yaklaşımı Amerikan dindarlığı üzerine uygulayan Glock ve Stark, temel dindarlık boyutlarından inanç, ibadet, tecrübe ve bilgi boyutları ile alt boyutlarını içeren bir indeks oluşturmuşlardır. İnanç boyutunu, ortodoks, partikularizm ve ahlak alt boyutlarma, ibadet boyutunu, toplu ibadetler ve bireysel ibadetler alt boyutlarına ayırarak, tecrübe boyutunu, tabiatüstü ile kurulan ilişki indeksi, bilgi boyutunu ise İncil bilgi indeksi oluşturarak incelemiştir. Onlar bu araştırmalarında dindarlığın etki boyutunu kullanmamışlardır ${ }^{35}$.

Bununla birlikte Batı'da yapılan bazı empirik çalışmalarda Glock'un dindarlığın boyutları kuramı, uygulamalı olarak araştırılmıştır. Nunnig, Glock'un dindarlık boyutlarına kiliseye karşı tutumlar boyutunu da ekleyerek yaptığı uygulamalı araştırmada bilgi boyutu dışındaki diğer boyutların bir-

32 Joseph E. Faulkner-G.F. DeJong, "Religiosity in 5-D: an Emprical Analysis, Social Forces, Say1, 45, 1966, 246-254; J.P. Robinson-P.R. Shaver, a.g.e., s. 564.

33 Kevin J. Christiano, William H. Swatos Jr., Peter Kivisto, Sociology of Religion, New York, Oxford, 2002, s. 31.

34 Rodney Stark-Charles Y. Glock, "Dimension of Religious Committment", (ed. Roland Robertson), Sociology of Religion, New York, 1976, s. 253-256; Charles Y. Glock, "Dindarlı̆̆ın Boyutları Üzerine", Din Sosyolojisi, (çev. M. Emin Köktaş), Konya, 1998, s. 252-253.

35 J.P. Robinson-P.R. Shaver, a.g.e., s. 556. 
birleriyle oldukça sıkı bir ilişki içinde oldukları bulgusuna ulaşmıştır. Bu nedenle $\mathrm{O}$, dinî zihniyetin çok boyutlu olmadığı sonucuna ulaşmıştır. Faktör analizi neticesinde Glock'un birbirinden bağımsız dindarlık boyutlarını doğrulayamamıştır. Faktör analizine göre inanç, ibadet, tecrübe ve etki boyutları "genel dindarlık" boyutunda toplanmış, bilgi ve kilise cemaatine bağlılık ayrı boyutlar olarak kalmıştır ${ }^{36}$.

Clayton ve Gladden ise dinin sadece inanç boyutunun olduğunu ileri sürmüşlerdir. Onlara göre Batı'da Glock ve Stark'ın kuramı eleştirel bir yaklaşımla ele alınmamış ve sanki aksi ispat edilemeyecek bilimsel bir gerçek olarak kabul edilmiştir. Onlar, Faulkner ve Dejong'un çok boyutlu dindarlık ölçeğini, üniversite öğrencileri üzerine uygulamışlardır. Elde ettikleri datalar üzerinde yaptıkları faktör analizi ve korelasyonlar neticesinde dinin inançtan ibaret tekbir boyutunun olduğunu göstermişlerdir. Clayton ve Gladden'e göre Glock ve Stark çok boyutlu dindarlık yaklaşımını, Hıristiyan denekler üzerine uygulamışlar ve elde edilen sonuçları, başka dinler üzerine araştırma yapmadan genellemişlerdir. Bununla birlikte dindarlığı Hıristiyan geleneğine aykırı olmasına rağmen kendilerini Hıristiyan görenler de vardır. Onlara göre bu problemler çözülmeden genellemelere gitmek yanıltıcı sonuçlara götürür ${ }^{37}$.

\section{Sonuç}

Görüldüğü gibi din sosyolojisinde dindarlık ve dindarlık ölçme problemi üzerine yapılan tartışmaların uzun bir geçmişi vardır. Geçmişten günümüze din sosyolojisinde dindarlığın sosyolojik olarak nasıl ölçülmesi gerektiği sorununun çözümüne yönelik bazı yaklaşımlar sunulmasına rağmen bu sorun henüz çözüme kavuşturulamamıştır. Din sosyolojisinde yapılan dindar tanımları birçok soruyu cevapsız bırakmaktadır. Farklı dindarlık tanımı ve ölçütleri kullanan yaklaşımlar, birbiriyle çatışan araştırma bulgularına ulaşmışlardır. Çünkü, dinî inançların çeşitliliği, dindarlığın tanımını yapmayı ve dindarlığa yönelik bazı ölçütler geliştirmeyi güçleştirmektedir ${ }^{38}$. Bu nedenle din sosyologları, ileri sürülen dindarlık tanımları ve dindarlık boyutlarına birçok eleştiri getirmişlerdir. Bu açıdan, bazı sosyologlar da dindarlığı oluşturan unsurlarla ilgilenmişler ve dindarlıkla diğer faktörler arasındaki ilişkiyi ölçmeyi amaçlamışlardır. Onun için bir çok dindarlık öl-

36 M.E. Köktaş, a.g.e., s. 57.

37 R.R. Clayton-J.W. Gladden, "The Five Dimensions of Religiosty: Toward Demythologizing a Sacred Artifact", Journal for the Scientific Study of Religion, Say1, 13, 1971, s. 135-143.

38 I. Thompson, a.g.e., s.9. 
çeği geliştirmişlerdir. Bu ölçekler arasında Glock ve Stark'ın geliştirdiği dindarlığın boyutları yaklaşımı bir çok din sosyologunun ilgisini çekmiştir. Neticede "dindarlığın boyutları", dindarlığın temel karakteristiklerini belirlemede büyük bir kolaylık sağlayabilir. Ancak bu boyutları ölçülebilir araçlar haline dönüştürmede, bunları ölçebilmede ve boyutlar arasındaki farklılaşmaları ortaya koymada hala zorluklar olduğu anlaşılmaktadır.

Buna rağmen din sosyolojisi çalışmalarında dindarlık, empirik bir araştırma problemi olarak tanımlanmaktan geri durulmamıştır. Çünkü, bireysel ve toplumsal dindarlığı temel araştırma alanı olarak seçiyorsak, dindarlık tanımı ve dindarlığın karakteristiklerini belirleyen ölçütlerden hareket etmek zorunlu olmaktadır. Thomson'un da dediği gibi "analiz edilecek şeyi belirlemeden analizin nasıl yapılacağını kavramak güçtür. Ayrıca tanımlar şüphe götürür olabilir ve biz bunları inceledikten sonra üzerinde birtakım değişiklikler yapmak isteyebiliriz. Ama bu tanımların birinden başlamamız gerekir"39. Anlaşılan, din sosyolojisinde dindarlık, dindarlığın nitelikleri gibi kavramlarla ilgili tanım ve yaklaşımlar ve dindarlığın sosyolojik olarak, objektif bir biçimde nasıl araştırılabileceği tartışmaları sürüp gidecektir. 